\title{
Extraction-Spectrophotometric Determination of Trace Amounts of Barium by 18-Crown-6 and Rose Bengal
}

\author{
Hooshang PARHAM ${ }^{\dagger}$ and Abbass G. Fazeli \\ Department of Chemistry, Faculty of Science, Azad University, Gachsaran, Iran
}

\begin{abstract}
A simple and sensitive extraction-spectrophotometric method for the determination of barium is reported. The 18C6barium-Rose Bengal (18C6-Ba-RB) ternary complex was quantitatively extracted into dichloromethane, and its absorbance was measured at $565 \mathrm{~nm}$. The calibration graph is linear over a barium concentration range of $0.083-4.70 \mu \mathrm{g}$ $\mathrm{ml}^{-1}$. The limit of detection of barium was $17.7 \mathrm{ng} \mathrm{ml}^{-1}$. The relative standard deviation (RSD) of ten replicate measurements was $2.19 \%$ for a $0.83 \mu \mathrm{g} \mathrm{ml}^{-1}$ barium solution. The interference effects of various cations and anions were also studied and reported. The described method provides a simple and reliable means for determination of trace amounts of barium in real samples.
\end{abstract}

(Received October 21, 1999; Accepted January 31, 2000)

Liquid-liquid extraction methods for the separation and determination of barium are limited. Macrocyclic crown ethers are well known as selective ligands for various ions. ${ }^{1}$ Some such complexes can be extracted from aqueous solutions into an organic phase. Although the extraction properties of crown ether complexes have been widely studied, ${ }^{2-9}$ their applications to the determination of metal ions are still rather limited. ${ }^{10-17}$ The application of highly molar absorbance anionic dyes or counter anions with large molar absorptivities could lead to a sensitive method for trace metal determinations.

In this paper, we report a simple and sensitive method for the quantitative extraction of the 18C6-Ba-RB ternary complex into dichloromethane, followed by spectrophotometric measurements at $565 \mathrm{~nm}$.

\section{Experimental}

\section{Reagents and chemicals}

All of the chemicals used were of the highest purity available, and were used without further purification. Double-distilled deionized water was used throughout.

Stock solutions of barium $\left(1000 \mu \mathrm{g} \mathrm{ml}^{-1}\right)$, Rose Bengal $(2.0 \times$ $\left.10^{-4} \mathrm{M}\right)$ and 18-crown-6 $\left(4.0 \times 10^{-3} \mathrm{M}\right)$ were prepared.

\section{Apparatus}

The absorption spectra were recorded on a UV-240 spectrophotometer (Shimadzu). A Model 550S spectrophotometer (Perkin-Elmer) was used for absorbance measurements.

\section{Procedure}

After an aliquot of a sample containing $0.83-47 \mu \mathrm{g} \mathrm{ml}^{-1}$ of barium was placed in a $10 \mathrm{ml}$ volumetric flask, $4 \mathrm{ml}$ of Rose Bengal solution $\left(2.0 \times 10^{-4} \mathrm{M}\right)$ and $4 \mathrm{ml}$ of $18 \mathrm{C} 6$ solution $(4.0 \times$ $\left.10^{-3} \mathrm{M}\right)$ were added; the solution was then diluted to the mark with distilled water. The solution was transferred into a $50 \mathrm{ml}$

\footnotetext{
† To whom correspondence should be addressed.

E-mail: Parham@Ahvazuniv.Neda.ir
}

separatory funnel and $8 \mathrm{ml}$ of dichloromethane was added. The solution was shaken vigorously for $1 \mathrm{~min}$. After the phases were allowed to separate, the organic phase was separated, and its absorbance was measured at $565 \mathrm{~nm}$ against a reagent blank.

\section{Results and Discussion}

Since $\mathrm{Ba}^{2+}$ ion forms a fairly stable 1:1 complex with $18 \mathrm{C} 6$ in aqueous solution, ${ }^{1}$ the application of an anionic dyestuff as a counter ion was expected to result in a sensitive and useful method for a trace barium ion determination.

In preliminary experiments, it was found that the counter anion plays an important role in the formation of a stable ternary complex; among the dyestuffs examined (Alizarin Yellow R (AYR), Methyl Orange (MO), Rose Bengal (RB)), the best results were obtained with Rose Bengal (the molar absorptivities of extracted complexes were: $\varepsilon_{\mathrm{RB}}=1.69 \times 10^{5}, \varepsilon_{\mathrm{MO}}=1.34 \times 10^{2}, \varepsilon_{\mathrm{AYR}}$ $=23$ ). Many ternary complexes which are extractable into organic solvents, such as chloroform, carbon tetrachloride and 1,2dichloromethane, are reported using Rose Bengal as a counter ion. ${ }^{18}$ The formula of the complex was determined by Job's method, and the results show a mole ratio of $1: 1: 1$ for 18C6:Ba:RB.

\section{Effect of variables}

The influence of the $\mathrm{pH}$ on the extraction of the 18C6-Ba-RB complex was studied over the $\mathrm{pH}$ range $2-12$; the results are shown in Fig. 1. As can be seen, the maximum extraction of the barium complex occurs within the $\mathrm{pH}$ range $8-10$. In this $\mathrm{pH}$ range, the dyestuff is mainly in the form $\mathrm{RB}^{2-}$, which is suitable for ion-pair formation with the $18 \mathrm{C} 6-\mathrm{Ba}^{2+}$ complex.

The effect of the Rose Bengal (RB) and 18C6 concentration on the extraction of the 18C6-Ba-RB complex was investigated; and the results are shown in Figs. 2 and 3, respectively. As can be seen, the absorption of the organic phase increases with increasing both the RB and $18 \mathrm{C} 6$ concentrations in the aqueous phase. The maximum extraction of barium occurs when the reagent-to-metal ion mole ratio is about 14 for $\mathrm{RB}$, and about 


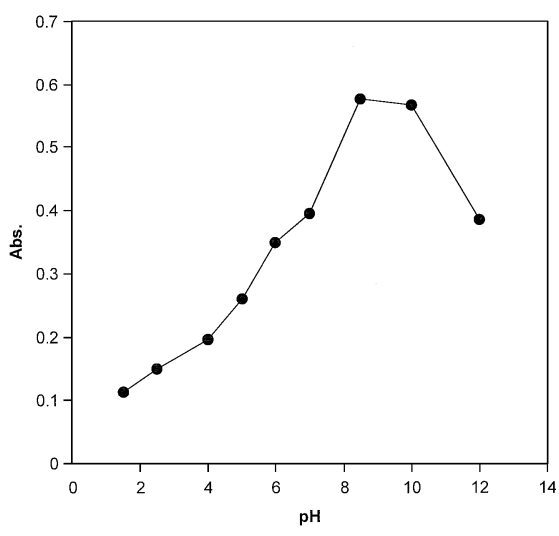

Fig. 1 Effect of the $\mathrm{pH}$ of the aqueous phase on the extraction of barium into the organic phase. Conditions: $\mathrm{Ba}^{2+}, 0.60 \mu \mathrm{g} \mathrm{ml}^{-1}$; $18 \mathrm{C} 6$, $5 \times 10^{-4} \mathrm{M}$; Rose Bengal, $1.0 \times 10^{-4} \mathrm{M}$; dichloromethane, $8 \mathrm{ml}$; shaking time, $1 \mathrm{~min}$.

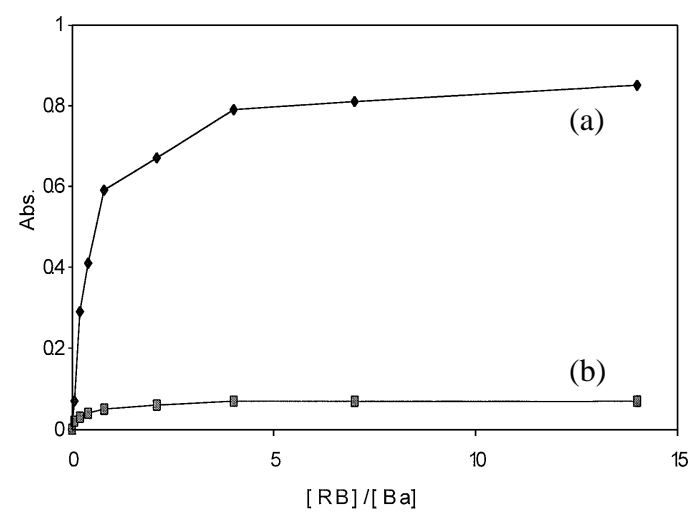

Fig. 2 Effect of the Rose Bengal concentration on the extraction of barium. Conditions: (a) $\mathrm{Ba}^{2+}, 0.83 \mu \mathrm{g} \mathrm{ml}^{-1} ; 18 \mathrm{C} 6,5 \times 10^{-4} \mathrm{M}$; dichloromethane, $8 \mathrm{ml}$; shaking time, $1 \mathrm{~min}$, and (b) $\mathrm{Ba}^{2+}, 0.0 \mu \mathrm{g}$ $\mathrm{ml}^{-1}$; all other conditions are the same as those in (a).

70 , in the case of 18C6. A further excess of both reagents has no considerable effect on the measured absorbance, except that in the case of RB the absorbance of the blank solution tends to gradually increase.

The extraction of the 18C6-Ba-RB ternary complex under the condition recommended in the procedure is rapid. A shaking time of $1 \mathrm{~min}$ was found to be sufficient for extracting complexes.

The effect of the ionic strength on the extraction of the ternary barium complex was studied by using $\mathrm{LiCl}, \mathrm{LiNO}_{3}$ and $\mathrm{KNO}_{3}$. The results showed no considerable effect in the concentration range $0.00-0.05 \mathrm{M}$ of $\mathrm{LiCl}, \mathrm{LiNO}_{3}$ salts, though a considerable effect was seen in the concentration range $1 \times 10^{-4}-0.05 \mathrm{M}$ of $\mathrm{KNO}_{3}$, which is due to an interference effect of the potassium ion.

The extraction process was performed under optimal conditions with some common organic solvents, such as 1,2-dichloromethane, chloroform, carbon tetrachloride, methyl isobuthyl ketone and benzene. It was found that the ternary complex is readily extractable in 1,2-dichloromethane. However, in the other solvents used, the colored complex could not be extracted into the organic phase as completely as that which occurred in 1,2dichloromethane.

It must be mentioned that the quantitative extraction of barium as its ternary comple ${ }^{18}$ was completed by single-stage extraction with $8 \mathrm{ml}$ of the organic phase under optimal experimental

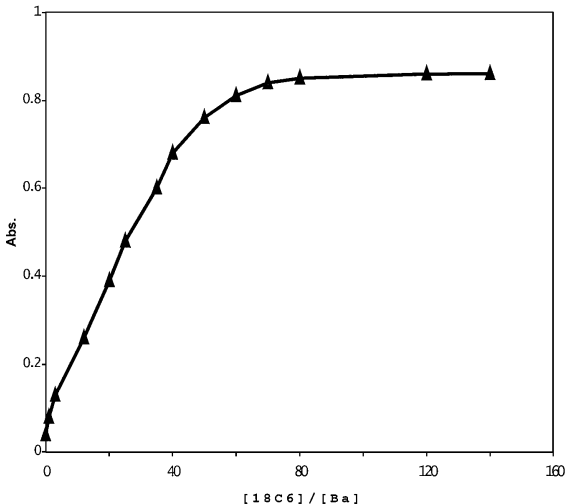

Fig. 3 Effect of the $18 \mathrm{C} 6$ concentration on the extraction of barium. Conditions: $\mathrm{Ba}^{2+}, 0.83 \mu \mathrm{g} \mathrm{ml}^{-1}$; Rose Bengal, $1.0 \times 10^{-4} \mathrm{M}$; dichloromethane, $8 \mathrm{ml}$; shaking time, $1 \mathrm{~min}$.

conditions.

\section{Calibration graphs and precision}

Under the optimum conditions described above, a linear calibration graph was obtained in the concentration range 0.083 - $4.17 \mu \mathrm{g} \mathrm{ml}^{-1}$ for barium. The regression equation, $A=2.02 \times$ $10^{4} C_{\mathrm{Ba}}+0.065$ (where $A$ is the absorbance of the complex and $C_{\mathrm{Ba}}$ is the molar concentration of barium ions), and a correlation coefficient of 0.9997 were obtained. The results are shown in Fig. 4. The relative standard deviation (RSD) of ten replicate measurements was $2.19 \%$ for a $0.83 \mu \mathrm{g} \mathrm{ml}^{-1}$ barium solution.

\section{Effect of diverse ions}

In order to study the influence of various cations and anions on the determination of barium ions, a fixed concentration of barium $\left(0.83 \mu \mathrm{g} \mathrm{ml}^{-1}\right)$ was taken with different amounts of foreign ions, and the recommended procedure was followed. A relative error of twice the standard deviation of the measurement was considered to be tolerable. The results are summarized in Table 1 along with the maximum tolerance limit for each ion. As can be seen, most of the cations and anions used had no considerable effect on the determination of barium ions. However, potassium and strontium ions were found to interfere with the barium determination.

\section{Application}

In order to evaluate the applicability of the proposed method for the determination of barium in a real sample, the proposed method was applied to the determination of barium in boiled raw water of Karkheh river. The results are given in Table 2. As can be seen, there is a satisfactory agreement between the results of the proposed method and standard atomic absorption method for the barium determination, respectively.

The described method provides a simple and reliable means for the determination of trace amounts of barium in real samples. The linear concentration range of the proposed method for barium is much wider compared with those of some previously reported methods. ${ }^{19-21}$ The method compares favorably in both sensitivity and selectivity with most of the published methods for the determination of barium by using ion-association compounds and it can thus certainly be placed among the most sensitive ones.

\section{References}

1. R. M. Izatt, K. Pawlak, J. S. Bradshaw, and R. L. Bruening, 


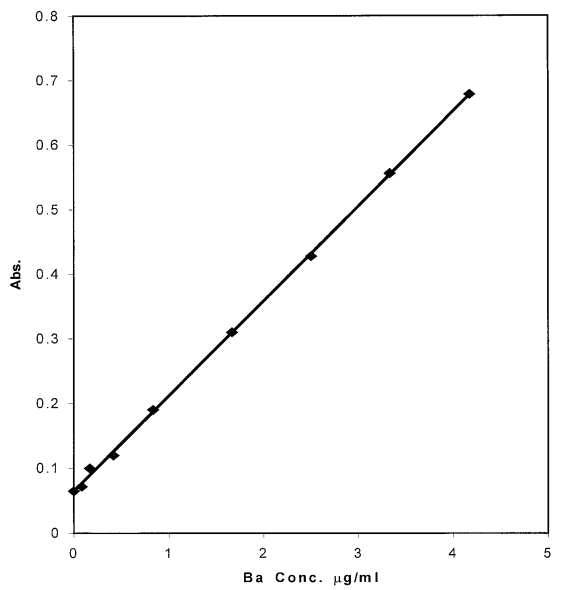

Fig. 4 Calibration graph for the determination of barium Conditions: $18 \mathrm{C} 6,1.0 \times 10^{-2} \mathrm{M}$; Rose Bengal, $5.0 \times 10^{-3} \mathrm{M}$; dichloromethane, $8 \mathrm{ml}$; shaking time, $1 \mathrm{~min}$.
Table 1 Effect of foreign ions on the determination of $0.83 \mu \mathrm{g} \mathrm{ml}^{-1}$ barium under optimum conditions

\begin{tabular}{lc}
\hline \multicolumn{1}{c}{ Species } & $\begin{array}{c}\text { Tolerance limit of } \\
\text { ion to Ba or } \mathrm{K}\end{array}$ \\
\hline $\mathrm{Li}^{+}, \mathrm{Cl}^{-}, \mathrm{NO}_{3}^{-}$ & 1500 \\
$\mathrm{Cu}^{2+}, \mathrm{Zn}^{2+}, \mathrm{Cd}^{2+}, \mathrm{Ni}^{2+}, \mathrm{Co}^{2+}$, & \\
$\mathrm{Ce}^{4+}, \mathrm{Ce}^{3+}, \mathrm{V}^{4+}, \mathrm{Bi}^{3+}$, & 500 \\
$\mathrm{CN}^{-}, \mathrm{ClO}_{3}^{-}, \mathrm{ClO}_{4}^{-}, \mathrm{SCN}^{-}$, & \\
$\mathrm{Br}^{-}, \mathrm{I}^{-}, \mathrm{F}^{-}, \mathrm{CH}_{3} \mathrm{COO}^{-}$ & 300 \\
$\mathrm{Pd}^{2+}, \mathrm{Sn}^{2+}, \mathrm{La}^{3+}, \mathrm{Na}^{+}$ & 200 \\
$\mathrm{Ca}^{2+}, \mathrm{Mn}^{2+}, \mathrm{Tl}^{+}, \mathrm{NH}_{4}^{+}$, & \\
$\mathrm{P}_{2} \mathrm{O}_{7}+\mathrm{PO}_{4}{ }^{3-}, \mathrm{C}_{2} \mathrm{O}_{4}{ }^{2-}, \mathrm{CO}_{3}{ }^{2-}$ & 50 \\
$\mathrm{Hg}^{2+}, \mathrm{Pb}^{2+}, \mathrm{Ag}^{+}$ & $1^{\mathrm{a}}$ \\
$\mathrm{Al}^{3+}, \mathrm{Mg}^{2+}, \mathrm{Fe}^{2+}, \mathrm{Fe}^{3+}$ & $5^{\mathrm{b}}$ \\
$\mathrm{Sr}^{2+}$ & 1 \\
$\mathrm{~K}^{+}$ & 3 \\
$\mathrm{SO}_{4}{ }^{2-}$ & 5 \\
\hline
\end{tabular}

a. The interference of these cations was eliminated by the addition of $1 \mathrm{ml}$ of $1 \times 10^{-3} \mathrm{M}$ of a sodium cyanide solution.

b. The interference of these cations was eliminated by adding $0.5 \mathrm{ml}$ of diethylene glycol.

Table 2 Determination of barium in Karkheh river raw water

\begin{tabular}{lcccccc}
\hline \multirow{2}{*}{ Method } & \multicolumn{3}{c}{ Barium $/ \mu \mathrm{g} \mathrm{ml}^{-1}$} & \multicolumn{2}{c}{ Potassium $/ \mu \mathrm{g} \mathrm{ml}^{-1}$} \\
\cline { 2 - 7 } & Content & RSD & Content & RSD & Content & RSD \\
\hline Proposed method & $1.22^{\mathrm{a}}$ & 3.52 & $0.19^{\mathrm{b}}$ & 5.2 & - & - \\
Atomic absorption method & $1.20^{\mathrm{a}}$ & 2.0 & $0.18^{\mathrm{b}}$ & 4.8 & - & $1.71^{\mathrm{c}}$ \\
Flame photometric method & - & - & - & - & 3.2 \\
\hline
\end{tabular}

RSD $=$ relative standard deviation for $n=5$. a. After the addition of $1.0 \mu \mathrm{g} \mathrm{m}^{-1}$ of barium to the river-water sample. b. No standard solution of barium was added to the river-water sample. c. This amount of potassium was not detected by the proposed method.

Chem. Rev., 1991, 91, 1721.

2. A. Ohki, P. J. Lu, and R. A. Barstch, Anal. Chem., 1994, 63, 2282.

3. K. Suzuki, K. Watanabe, Y. Matsumoto, M. Kobayashi, S. Sato, D. Siswanta, and H. Hisamoto,. Anal. Chem., 1995, $64,324$.

4. A. R. Fakhari, M. R. Ganjali, and M. Shamsipur. Anal. Chem., 1997, 69, 3693.

5. Y. Takada, Bull. Chem. Soc. Jpn., 1979, 52, 2501.

6. M. Yoshio and H. Nogushi, Anal. Lett., 1982, 15, 1197.

7. L. M. Tsay, J. S. Shih, and S. C. Wu, Analyst, 1983, 108 , 1108.

8. B. G. Cox, E. Buncel, H. S. Shin, R. A. B. Bannard, and J. G. Purdon, Can. J. Chem., 1986, 64, 920.

9. H. Koshima and H. Onishi, Analyst, 1986, 111, 1261.

10. K. Nakagawa, S. Okada, Y. Inoue, and A. Tai, Anal. Chem., 1988, 60, 2527.

11. N. V. Derokar and S. M. Khopkar, Bull. Chem. Soc. Jpn., 1991, 64, 1962.
12. K. Chayama and E. Sekido, Anal. Chim. Acta, 1991, 248, 511.

13. H. Sumiyoshi and K. Nakahara, Talanta, 1977, 24, 763.

14. M. Takagi, H. Nakamura, Y. Sanui, and K. Ueno, Anal. Chim. Acta, 1981, 126, 185.

15. G. E. Pacey and Y. P. Wu, Talanta, 1984, 31, 165.

16. R. Escobar, C. Lamoneda, F. Depablos, and A. Guiraum, Analyst, 1989, 114, 533.

17. S. Dadfarnia and M. Shamsipur, Anal. Lett., 1992, 25, 11.

18. A. K. De, S. M. Khopkar, and R. A. Chalmers, "Solvent Extraction of Metals", 1970, Van Nostrand Reinhold Series in Analytical Chemistry, New York, Cincinati, Torento, Melbourne, 32.

19. R. Ying and G. Yuhua, Fenxi Hиахиe, 1988, 18, 654.

20. Z. Pinggen and L. Jianyan, Huaxue Fence, 1993, 28, 372.

21. L. A. Kaplan and A. J. Pesce, "Clinical Chemistry", 1984, The C. V., Mosby Company, St. Louis, Torento, Princeton, 1075 . 